\title{
Long-Term, Autonomous Measurement of Atmospheric Carbon Dioxide Using an Ormosil Nanocomposite- Based Optical Sensor
}

\author{
Final Technical Progress Report
}

October 11, 2005

\author{
Grant Information: \\ Grant No.: DE-FG02-04ER83980 \\ Period of Performance: 07/13/2004 to 04/12/2005 \\ Reporting Period: 07/13/2004 to 04/12/2005 \\ Report Number: Final Report-10/05-3005-DOE-Carbon \\ Sponsor: \\ U.S. Department of Energy
}

DOE Project Officer:

Dr. Roger C. Dahlman

(301) 903-4951

Contractor:

InnoSense LLC

25970 Eshelman Avenue

Lomita, CA 90717

Principal Investigator:

Kisholoy Goswami, Ph.D.

(310) 530-2011

\section{SBIR/STTR RIGHTS NOTICE}

These SBIR/STTR data are furnished with SBIR/STTR rights under Grant No.DE-FG0204ER83980. For a period of 4 years after acceptance of all items to be delivered under this grant, the Government agrees to use these data for Government purposes only, and they shall not be disclosed outside the Government (including disclosure for procurement purposes) during such period without permission of the grantee, except that, subject to the foregoing use and disclosure prohibitions, such data may be disclosed for use by support contractors. After the aforesaid 4-year period the Government has a royalty-free license to use, and to authorize others to use on its behalf, these data for Government purposes, but is relieved of all disclosure prohibitions and assumes no liability for unauthorized use of these data by third parties. This Notice shall be affixed to any reproductions of these data in whole or in part. 


\section{EXECUTIVE SUMMARY}

The goal of this project is to construct a prototype carbon dioxide sensor that can be commercialized to offer a low-cost, autonomous instrument for long-term, unattended measurements. Currently, a cost-effective $\mathrm{CO}_{2}$ sensor system is not available that can perform cross-platform measurements (ground-based or airborne platforms such as balloon and unmanned aerial vehicle (UAV)) for understanding the carbon sequestration phenomenon. The $\mathrm{CO}_{2}$ sensor would support the research objectives of DOE-sponsored programs such as AmeriFlux and the North American Carbon Program (NACP).

Global energy consumption is projected to rise $60 \%$ over the next 20 years and use of oil is projected to increase by approximately $40 \%$. The combustion of coal, oil, and natural gas has increased carbon emissions globally from 1.6 billion tons in 1950 to 6.3 billion tons in 2000 . This figure is expected to reach 10 billon tons by 2020. It is important to understand the fate of this excess $\mathrm{CO}_{2}$ in the global carbon cycle. The overall goal of the project is to develop an accurate and reliable optical sensor for monitoring carbon dioxide autonomously at least for one year at a point remote from the actual $\mathrm{CO}_{2}$ release site.

In Phase I of this project, InnoSense LLC (ISL) demonstrated the feasibility of an ormosil-

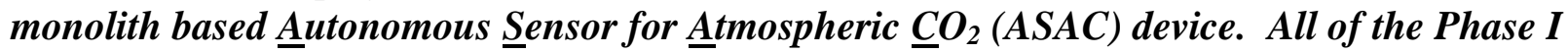
objectives were successfully met. Important Phase I results include:

Sensitivity to 0.4 ppm $\mathrm{CO}_{2}:$ : The sensor exhibited a minimum detection limit of $0.4 \mathrm{ppm}$.

Response Time of $<1$ minute: The $\mathrm{T}_{90}$ (time for the response signal to reach $90 \%$ of its final value) for the sensor was on the order of forty seconds.

Complete Reversibility: ISL demonstrated that the $\mathrm{CO}_{2}$ sensor was completely reversible.

Longer Operational Life: Utilizing a technique of continuous rehydration, the sensor was rendered operational during the Phase I test period of 2 months. Potential for one-year operational life has been established by extrapolation. To our knowledge, this sensing approach has not been reported. 
Carbon sequestration refers to the provision of long-term storage of carbon in the terrestrial biosphere, underground, or the oceans so that the buildup of carbon dioxide (the principal greenhouse gas) concentration in the atmosphere will reduce or slow. Precise knowledge of $\mathrm{CO}_{2}$ partitioning into these sinks has important implications for the global climate modeling and energy policy making. In February 1999, the U.S. Department of Energy released a 200page "working draft" detailing the emerging science and technology of carbon sequestration the capture and secure storage of carbon dioxide emitted from the combustion of fossil fuels [Source: DOE Report "Carbon Sequestration State of the Science: A Working Paper for Roadmapping Future Carbon R\&D," http://www.netl.doe.gov/publications/press/1999/seqrpt.pdf]. According to that report, the Intergovernmental Panel on Climate Change has forecasted that under "business as usual" conditions, global emissions of carbon dioxide could triple from 7.4 billion tons of carbon per year in 1997 to approximately 20 billion tons per year by 2100. The panel also warned that concentrations of carbon dioxide in the earth's atmosphere could double by the middle of the $21^{\text {st }}$ century and continue to build up even faster in later years, potentially creating a variety of serious environmental consequences. Section 5.3.6 of the previously mentioned report (page 5-16) states that tracking of the distribution of $\mathrm{CO}_{2}$ in air and trapped in dissolved or solid phases is needed for verifying the successes of carbon sequestration activities.

Thus, advancing our understanding of the carbon sequestration pathways requires a $\mathrm{CO}_{2}$ sensor capable of long term, highly accurate, autonomous, and in situ measurements. It is desirable that these sensors exhibit total autonomy, high measurement precision, suitable frequency of measurement (many times per day), and long deployment lifetimes. $\mathrm{CO}_{2}$ concentrations are currently determined offsite using air samples collected in bags or flasks with gas chromatographs. This approach is limiting with respect frequency of measurements and lag time between sample collection and analysis. ${ }^{1(d)}$ Issues such as sample storage and transport are also concerning. Continuous $\mathrm{CO}_{2}$ monitoring by infrared absorption techniques offer reliable data on a fast time scale $(0.1 \mathrm{~s})$. However, such instruments are often bulky and not particularly robust. Electrochemical sensors, utilizing membranes and scrubbers, are popular for $\mathrm{CO}_{2}$ measurements. However, their use is mostly limited to short-term measurements because of issues such as electrolyte drying and calibration.

For long-term and unattended sensor operation, InnoSense LLC (ISL) has completed the design of sensor addressing issues including power requirement, calibration, performance under all weather conditions, temperature-corrected sensor response and data transmission to climate research centers. Figure 1-1 shows an artist's rendering of the application of the device. 
This Final Report complies with SBIR Rights notice set forth in FAR clause 52.227-20

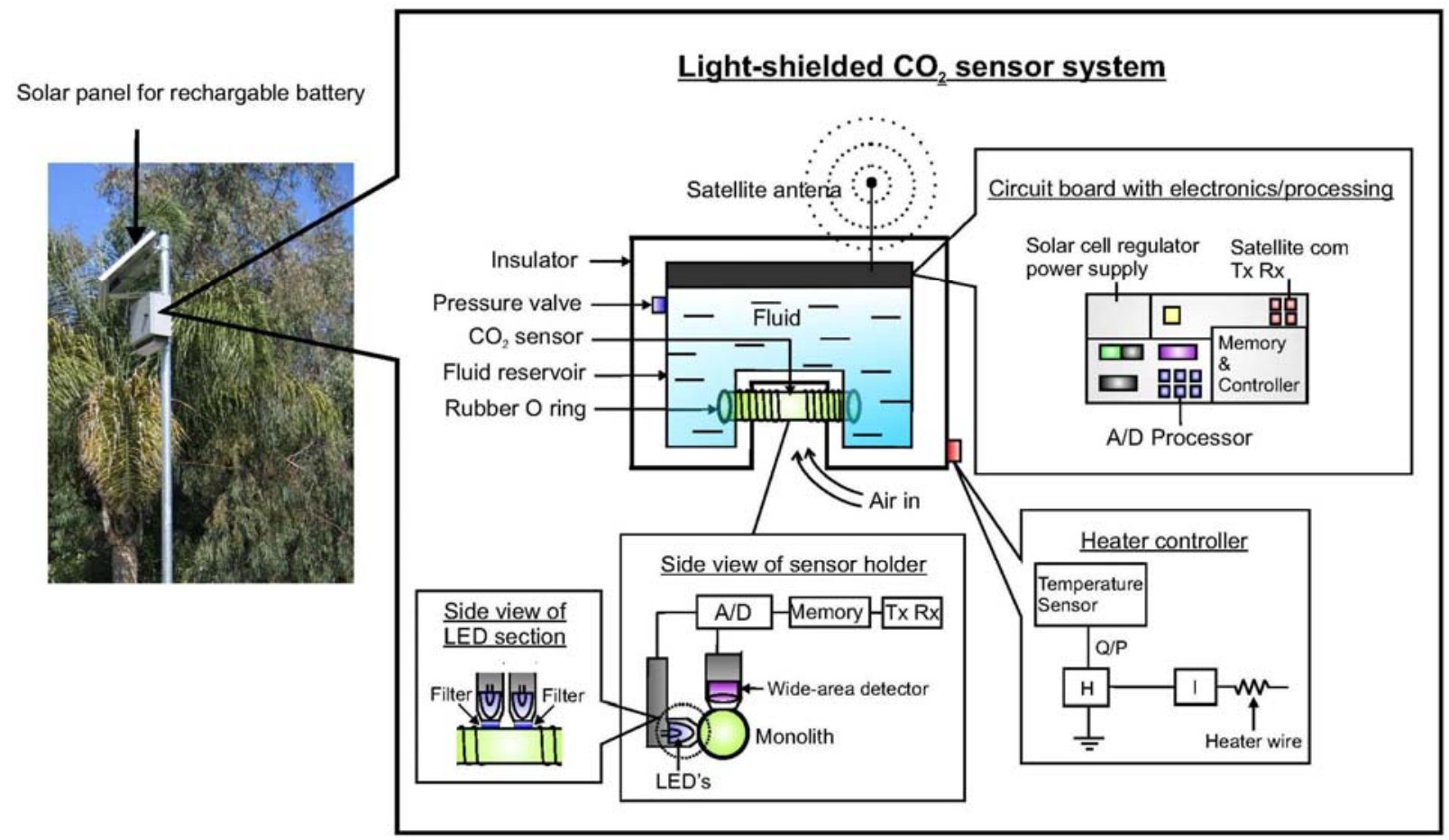

Figure 1-1

An artist's rendition of a ground-based deployment scenario for the sensor system. Details on the device follow.

Previous experience of the Principal Investigator and other researchers (discussed in Section 1.2) shows that opto-chemical sensors for $\mathrm{CO}_{2}$ require daily to weekly calibration. This happens because the anionic form of the indicator is exhausted by continuous exposure to $\mathrm{CO}_{2}$, and the indicator matrix also dries out. One significant aspect of our sensor design is the continuous rehydration of the carbon dioxide indicator for maintaining its anionic form so that the sensor can operate without calibration for a year. The ASAC system consists of a reservoir containing a buffer $(\mathrm{pH} 8)$, which slowly migrates into the Organically Modified Silicate (ormosil)-based $\mathrm{CO}_{2}$ sensor monolith attached to the reservoir. The anionic form of the fluorescent $\mathrm{CO}_{2}$ indicator (8-hydroxypyrene-1,3,6-trisulfonic acid (HPTS)) undergoes a protonation-deprotonation equilibrium process as the $\mathrm{CO}_{2}$ concentration increases and decreases respectively. Upon protonation, the fluorescence intensity of HPTS decreases. In our design the sensor would remain reversible and longer-lasting because the base from the reservoir migrates into the ormosil matrix through the pores and channels of ormosil via capillary action. This transport process allows the $\mathrm{pH}$ in the sensing matrix to remain above 7 , a necessity for deprotonating the hydroxyl group of HPTS (pKa 7.3).

The sensing activity takes place at the middle of the monolith where the flow of buffer is comparatively restricted than at the ends of the monolith. Thus, this active sensing zone would just stay moist and not be flooded with the buffer. The continuous exposure of the sensor to atmospheric $\mathrm{CO}_{2}$ changes $\mathrm{pH}$ in the microenvironments of the pores within the ormosil monolith, creating a steady state condition for $\mathrm{CO}_{2}$ measurements. The sensing zone is deliberately chosen at the middle of the monolith to make sure that the buffering capacity of the buffer would not prevent $\mathrm{pH}$ changes to occur in response to $\mathrm{CO}_{2}$. The validation of this concept had been the subject of our Phase I investigation. 
Two LEDs that are pulsed alternatively (one LED as reference) are attached to the sensor sideways, as Figure 1-1 shows. Appropriate filters are utilized to select different excitation bands (detailed discussion appears in Section 5.1 under Task 4). A wide area photodetector is affixed orthogonally. Since photoluminescence emits in all solid angles, the emission light from HPTS due to both LEDs can be collected by the wide area photodetector. The pulsed LEDs are synchronized so that the photodetector gathers signal resulting from each LED separately for subsequent ratiometric analysis by the microprocessor. The LEDs and the photodetector can be configured across from each other also. A cut-off filter is used before the photodiode to exclude the excitation component from the luminescence signal. For field applications, the system would be powered by a solar battery with seven-day or more battery autonomy. The experimental data on $\mathrm{CO}_{2}$ levels can be stored locally prior to transmission via satellite or other appropriate communication means following a pre-programmed protocol. For preventing freezing of the aqueous buffer during winter, the sensor housing would be properly insulated with a thick pad of thermal insulation materials. The monolithic sensing element, which is open to air, would be heated with a resistor wire. The sensor housing is designed to prevent rain-water penetration, and for shielding the sensor from ambient light and turbulent air.

\subsection{Background and Technical Approach}

Opto-chemical sensors have been developed recently for in situ measurements of $\mathrm{CO}_{2}{ }^{2-18}$ These sensors utilize the fact that $\mathrm{CO}_{2}$ upon dissolution in water produces carbonic acid as shown by the following equilibrium processes:*

$$
\begin{array}{ll}
\mathrm{CO}_{2} \text { (air) }+\mathrm{H}_{2} \mathrm{O} \leftrightarrows \mathrm{CO}_{2} \text { (aq.) } & \mathrm{K}_{\mathrm{h}}=3.4 \times 10^{-2} \mathrm{M} / \mathrm{atm} \\
\mathrm{CO}_{2}(\mathrm{aq})+\mathrm{H}_{2} \mathrm{O} \leftrightarrows \mathrm{H}_{2} \mathrm{CO}_{3} & \mathrm{~K}=2.6 \times 10^{-3} \\
\mathrm{H}_{2} \mathrm{CO}_{3}+\mathrm{H}_{2} \mathrm{O} \leftrightarrows \mathrm{HCO}_{3}^{-}+\mathrm{H}_{3} \mathrm{O}^{+} & \mathrm{K}_{1}=1.7 \times 10^{-4} \mathrm{M} \\
\mathrm{HCO}_{3}{ }^{-}+\mathrm{H}_{2} \mathrm{O} \leftrightarrows \mathrm{CO}_{3}{ }^{2-}+\mathrm{H}_{3} \mathrm{O}^{+} & \mathrm{K}_{2}=5.6 \times 10^{-11} \mathrm{M}
\end{array}
$$

Where, $K_{h}$ is the Henry's law constant; $K$ is the equilibrium constant for carbonic acid formation; $\mathrm{K}_{1}$ and $\mathrm{K}_{2}$ are the first and second ionization constant for carbonic acid. In an aqueous solution of sodium bicarbonate it can be shown [see footnote below] that the relationship between the partial pressure of $\mathrm{CO}_{2}$ in air (i.e., $\mathrm{pCO}_{2}$ ) and $\left[\mathrm{H}^{+}\right]$is as follows:

$$
\alpha \mathrm{pCO}_{2}=\left\{\left(\left[\mathrm{H}^{+}\right]^{3}+\left[\mathrm{H}^{+}\right]^{2}\left[\mathrm{Na}^{+}\right]\right)-\mathrm{K}_{\mathrm{w}}\left[\mathrm{H}^{+}\right]\right\} /\left\{\mathrm{K}_{1}\left(\left[\mathrm{H}^{+}\right]+2 \mathrm{~K}_{2}\right)\right\}
$$

Where, $\alpha=\mathrm{K}_{\mathrm{h}} \mathrm{K}\left[\mathrm{H}_{2} \mathrm{O}\right], \mathrm{K}_{\mathrm{w}}$ is the water dissociation constant, and [ $\mathrm{Na}^{+}$] is the concentration of sodium ions present. Using a $\mathrm{pH}$ sensitive dye, where the anionic form of the dye is protonated, changes in medium $\mathrm{pH}$ can be detected and correlated to the partial pressure of $\mathrm{CO}_{2}$ in ambient air. In the first optical sensor for carbon dioxide, Opitz and Lubbers ${ }^{9}$ followed the fluorescence of 4-methylumbelliferone in a bicarbonate buffer to measure the $\mathrm{CO}_{2}$ partial pressure. Zhuzun and Seitz used 8-hydroxypyrene-1,3,6-trisulfonic acid (HPTS) in bicarbonate buffer utilizing a silicone membrane. ${ }^{10}$ For measurements in water, membranes

\footnotetext{
* Source: (a) P.W. Atkins, Physical Chemistry, Oxford University Press: Oxford, U.K., pp. 163-164, 1990. (b) M.A. Jensen, G.A. Rechnitz, "Response-time characteristics of the $\mathrm{pCO}_{2}$ electrode,” Analytical Chemistry, 51(12), pp. 1972-1977, 1979.
} 
This Final Report complies with SBIR Rights notice set forth in FAR clause 52.227-20

were used so that changes in the ambient $\mathrm{pH}$ were not mistakenly interpreted as change in the $\mathrm{CO}_{2}$ concentration. ${ }^{10,14}$ Care was taken so that other proton-producing components of smog $\left(\mathrm{SO}_{2}, \mathrm{NO}_{2}\right)$ did not mislead the results. Silicone membranes had been observed to allow preferential permeation for $\mathrm{CO}_{2}$.

The Principal Investigator of this proposal had studied HPTS in ethylcellulose matrix to construct a field-deployable fiber optic sensor. ${ }^{7}$ He found the operational lifetime of the sensor limited to only 3 weeks because the basicity of the medium dwindled gradually. For making a reversible $\mathrm{CO}_{2}$ sensor, the protonated dye needs to be deprotonated again, which requires the presence of base in the medium. The intensity change of a $\mathrm{CO}_{2}$ indicator can be affected by a variety of factors including stability of the indicator matrix, temperature fluctuations, and leaching and bleaching of the indicator. Response time may depend on lag time related to the permeation of $\mathrm{CO}_{2}$ through a membrane and equilibrium with the sensing medium. The need for frequent calibration is another concern.,14 The Principal Investigator has been active in this field, since late 1980s, and he is aware of these challenges. $3,7,15-17$

The ultimate target performance for the ASAC device appears in Table 1-1.

Table 1-1. Target Performance/Price Goal for the ASAC System

\begin{tabular}{|l|l|}
\hline \multicolumn{1}{|c|}{ Parameter } & \multicolumn{1}{c|}{$\mathbf{C O}_{2}$ Sensor } \\
\hline Dynamic Range & $\begin{array}{l}0-500 \mathrm{ppm} \text { in Air (The sensor is not limited to this range. } \\
\text { This range can be expanded easily) }\end{array}$ \\
\hline Response Time & $<1$ minute \\
\hline Accuracy & $\pm 5 \%$ of reading \\
\hline Resolution & 1 part in 3000 in dry air. \\
\hline Operating Temperature & -40 to $140^{0} \mathrm{~F}$ \\
\hline Operational Life & 12 months \\
\hline Device Cost & $\begin{array}{l}\$ 2,000\left(\mathrm{CO}_{2} \text { sensor system only; with solar battery and }\right. \\
\text { communication gear approximately } \$ 5,000)\end{array}$ \\
\hline Special Feature & Sensor Insensitive to motion/turbulence \\
\hline
\end{tabular}

\subsubsection{InnoSense LLC Approach Toward an Autonomous $\mathrm{CO}_{2}$ Sensor}

Before detailing the Phase I results, a discussion on the background of the technical approach is in order. 


\subsubsection{Fluorescent Indicator for Detecting Carbon Dioxide}

Having identified the issues that need to be resolved for developing a carbon dioxide sensor with longer operational life, InnoSense LLC utilized HPTS (8-hydroxypyrene1,3,6-trisulfonic acid, Figure 1-2), also called pyranine, as the indicator. The anionic form of the dye is highly fluorescent. In the presence of $\mathrm{CO}_{2}$, HPTS becomes protonated leading to a proportionate decrease in the fluorescence intensity, which is the basis for $\mathrm{CO}_{2}$ detection.

HPTS is an inexpensive indicator with a $\mathrm{pK}_{\mathrm{a}}$ of $\sim 7.3$ in aqueous buffers. It absorbs visible light $(400-500 \mathrm{~nm})$ very efficiently (molar absorptivity, $\varepsilon$, is $2 \times 10^{4} \mathrm{M}^{-1} \mathrm{~cm}^{-1}$ ),

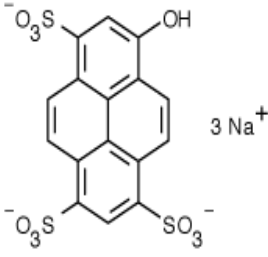

Figure 1-2

Structure of HPTS (8hydroxypyrene-1,3,6trisulfonic acid trisodium salt) and it also fluoresces in the visible range $(480 \mathrm{~nm}-560 \mathrm{~nm})$ with a high quantum yield $\left(\Phi_{\mathrm{f}} \sim\right.$ 0.96). Figure 1-3 shows changes in the HPTS absorption spectra as a function of $\mathrm{pH}$, and Figure 1-4 shows how HPTS undergoes changes in the excitation and emission profiles in different $\mathrm{pH}$ media.

The dotted curve in the excitation spectra (Figure 1-4) represents protonated HPTS with peak maximum at $410 \mathrm{~nm}$, and the solid excitation curves represent deprotonated HPTS (peak maxima at $460 \mathrm{~nm}$ ). The isosbestic point occurs at $420 \mathrm{~nm}$. ${ }^{6}$ The emission spectra undergo an increase in intensity from the protonated form to the deprotonated form, while the peak position remains unchanged at $513 \mathrm{~nm}$. Nivens et al. have utilized HPTS for $\mathrm{CO}_{2}$ detection by exciting the dye at $460 \mathrm{~nm}{ }^{6}$ Since highly powerful and inexpensive blue LEDs (Nichia) are available to excite HPTS at $460 \mathrm{~nm}$, the Principal Investigator selected HPTS to develop a low cost device. As Figures 1-3 and 1-4 show, changes in the absorption and excitation spectra closely match each other indicating that the $\mathrm{pH}$ interaction is purely a ground state phenomenon.

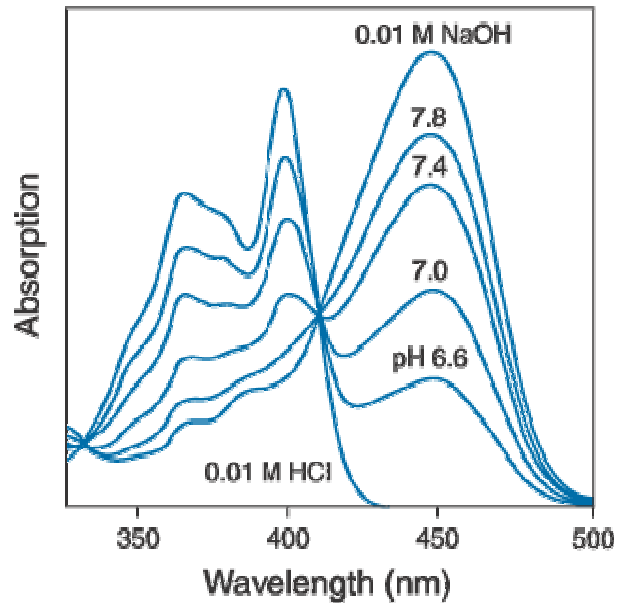

Figure 1-3

The $\mathrm{pH}$-dependent absorption spectra of 8hydroxypyrene-1,3,6-trisulfonic acid. [Source: Handbook of Fluorescent Probes and Research Products, Molecular Probes, Eugene, Oregon, http://www.probes.com/handbook/figures/0578.html.] 
This Final Report complies with SBIR Rights notice set forth in FAR clause 52.227-20

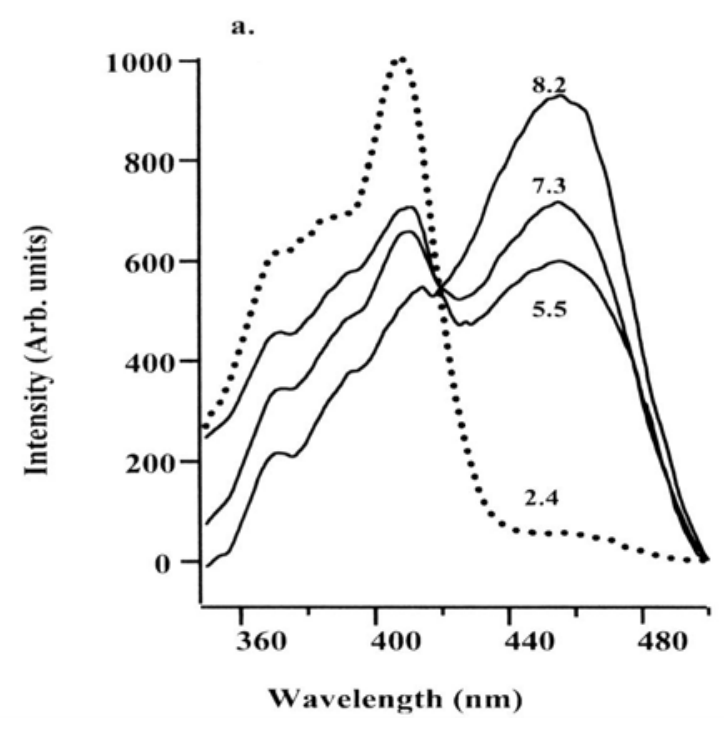

Excitation Spectra

Figure 1-4

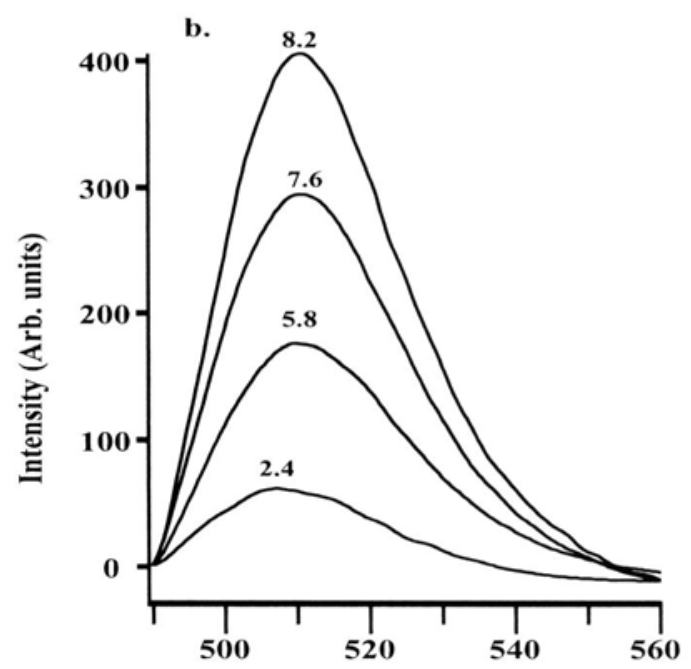

Emission Spectra

Excitation and emission spectra of HPTS as a function of $\mathrm{pH}$. The excitation spectra were generated by monitoring emission at $513 \mathrm{~nm}$, and the emission spectra were generated using $460 \mathrm{~nm}$ excitation. ${ }^{6}$

Equations (1-1) through (1-4) show a series of equilibria involving the formation of $\mathrm{H}_{2} \mathrm{CO}_{3}$ by $\mathrm{CO}_{2}$ in the aqueous phase. The protons from the acidic species $\left(\mathrm{H}_{2} \mathrm{CO}_{3}\right.$ or $\left.\mathrm{HCO}_{3}{ }^{-}\right)$, however, are consumed by the anionic form of HPTS. We have observed that when the sensor is left exposed to air, the sensitivity decreased drastically. This observation can be explained by the fact that the constant presence of $\mathrm{CO}_{2}$ in the atmosphere is a perpetual source of hydrogen ions. This destroys the internal buffering capacity of the sensor, rendering the sensor irreversible. We could regenerate the sensor by soaking it in a high $\mathrm{pH}$ buffer (pH 8-10). For autonomous operation of the ASAC system, we therefore incorporated a reservoir in our sensor design (Figure 1-1), which would contain a suitable buffer for hydrating the sensing matrix as well as maintaining the indicator at the proper anionic state.

Foundation of our working hypothesis that we can achieve a resolution of 1 part in 3000:

Referring to the excitation spectra of Figure 1-4, we calculated that the decrease of $\mathrm{pH}$ from 8.2 to 7.3 corresponded to an increase in hydrogen ion concentration by $4.5 \times 10^{-8} \mathrm{M}$. Considering that each $\mathrm{H}_{2} \mathrm{CO}_{3}$ molecule in the medium contributes one $\mathrm{H}^{+}\left(\right.$or $\mathrm{H}_{3} \mathrm{O}^{+}$) ion, then from Eqs. (1-1) and (1-2) we calculated that the change in the partial pressure of $\mathrm{CO}_{2}$ in air is $0.043 \mathrm{~mm} \mathrm{Hg}$ or $56 \mathrm{ppm}(\mathbf{p p m}=[($ vapor pressure in $\mathbf{~ m m ~} \mathbf{~ H g ~ x ~ 1 0 6}) / 760])$.

From the excitation spectra of Figure 1-4 we estimated that the signal count changed by 200 units when the $\mathrm{pH}$ value decreased form 8.2 to 7.3 corresponding to $56 \mathrm{ppm} \mathrm{CO}_{2}$. Thus, each intensity unit corresponded to $0.28 \mathrm{ppm}\left(56 \mathrm{ppm} / 200\right.$ units) of $\mathrm{CO}_{2}$. Assuming that the full scale intensity is recorded using a 12 bit A/D (analog to digital) data acquisition card, then each count of the A/D card corresponds to $0.07 \mathrm{ppm}$ ([1000 unit/4096 count] x [0.28 $\mathrm{ppm} / \mathrm{unit}]$ ). Assuming that the concentration of atmospheric $\mathrm{CO}_{2}$ is $350 \mathrm{ppm}$ and that we can differentiate each count of the $\mathrm{A} / \mathrm{D}$ card, then it is possible to detect one part of $\mathrm{CO}_{2}$ in 5000 parts ( $0.07 \mathrm{ppm}$ in $350 \mathrm{ppm}$ is equivalent to 1 part in 5000 parts). 


\subsubsection{Sensor Fabrication}

For making sensors, researchers use sol-gel technique and incorporate indicator moieties on optical fiber or planar waveguides. ${ }^{19-23}$ Sol-gel is a low temperature method of fabricating high quality optical glasses. Starting from molecular precursors in solution, an oxide glass network is produced through inorganic polymerization reactions. In a typical sol-gel process (Figure 15), a solution of a metal alkoxide (e.g., tetraethylorthosilicate, TEOS), water, and a suitable solvent (e.g., ethanol) is mixed in stoichiometric proportions to first make a "sol."

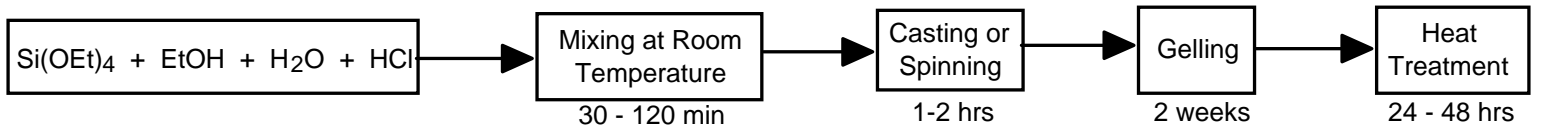

Figure 1-5

Sol-Gel approaches to fabricating waveguide monoliths

This "sol" then undergoes transition to a "gel," catalyzed by an acid or base. The gel is then dried to form a silica glass. Careful control of the ratio of the molecular precursors can produce a variety of glasses with defined properties. The indicator molecules can be an integral part of the "sol" or they can be uptaken by dip coating once the porous network is formed. The Principal Investigator has been personally involved in sol-gel based integrated optic (IO) sensor studies. ${ }^{19}$ The IO sensor, developed by his group contained a thin sol-gel film doped with an indicator for measuring oxygen. The sol-gel process is known to be influenced by a variety of parameters. Through numerous tests, Dr. Goswami’s group developed a process that yielded indicator-doped silica thin films on glass substrate with a fast response, high sensitivity, and good durability. The sol-gel synthesis was carefully controlled to achieve the desirable fast kinetics and minimal indicator loss. Of all the factors affecting sol-gel morphology and properties, the concentration and nature of catalysts in the sol-gel synthesis are the most important. Films prepared by acid and base catalysis were found to have distinctive surface morphologies, response times, and robustness.

Due to covalent linkage, sol-gels show excellent adhesion to glass. However, a major disadvantage of sol-gel derived silica sensors is that the materials retain a degree of hydrophilicity due to terminal Si-OH surface characteristics. Due to a continuous condensation reaction, the porous network within the sol-gel glass is always in a state of flux causing shrinkage and cracking of the structure. This leads to sensor drift. ${ }^{24}$ Steps to alleviate this problem has been introduced by selectively modifying the terminal surface characteristics. Hybrid inorganic-organic substrates, obtained with ormosils, offer a distinct advantage over silica-based materials for the optical detection of carbon dioxide. ${ }^{22}$

InnoSense LLC's approach for using organically modified silicates (ormosils) for incorporating the sensing materials has been inspired by available literature. Ormosils prepared from alkyl-derivatized alkoxylsilanes such as methyltrimethoxylsilane (MTMOS) or polydimethylsiloxane (PDMS) and a silicon alkoxide, offer a distinct advantage over silicabased materials. Adding these organic functionalities during the sol-gel process increases flexibility, and reduces silanol groups and gel-shrinkage. Thus, we expect the $\mathrm{CO}_{2}$ sensor not to show any aging effect commonly found in sol-gel glass sensors. Optical materials developed from these ormosils are often less brittle, and thus easier to fabricate a monolith 
This Final Report complies with SBIR Rights notice set forth in FAR clause 52.227-20

than those solely based on silica. ${ }^{25,26}$ Ormosils have been found to be nano-porous with unique properties, ${ }^{26}$ and the hybrid organic-inorganic materials have thus been termed nanocomposites.

\subsubsection{Innovations}

Careful considerations have been given to address issues related to long-term sensor operation. These issues include: (a) drying out of the buffer, (b) calibration, (c) drift, (d) sensitivity, and (e) accuracy. Our approach utilizes one type of ormosil to incorporate the HPTS indicator in the monolith and a second ormosil to act as a selective $\mathrm{CO}_{2}$ permeable membrane. This membrane is designed to be impermeable to water vapor for minimizing the evaporative loss of the buffer from the sensor surface. Excess evaporative loss is likely to make it harder to maintain HPTS in the proper anionic form. In addition, excess evaporative loss is like to clog the nanopores on the monolith with precipitated salts from the buffer. The Phase I study was designed to prove the hypothesis that constant rehydration with alkaline buffer would allow the $\mathrm{CO}_{2}$ sensor to remain sensitive and accurate for longer time. Thus, reproducible measurements can be made without recalibraton. Incorporation of a continuous rehydration mechanism has been our significant innovation. 
The ASAC system is designed to perform $\mathrm{CO}_{2}$ measurements in situ for up to a year. A series of these sensors, if triggered simultaneously or clocked synchronously, would show the time evolution of the $\mathrm{CO}_{2}$ concentration profile across the globe. The benefits of such instruments will be enormous. A successful $\mathrm{CO}_{2}$ detection system will significantly improve our understanding of terrestrial $\mathrm{CO}_{2}$ processes and assess the ecosystem response.

Benefits to DOE

A low-cost, autonomous and high resolution $\mathrm{CO}_{2}$ sensor would help DOE achieve its goal of cost savings by optimizing the utilization of resources for carbon sequestration activities. The joint Office of Fossil Energy and Office of Science April 1999 draft report, Carbon Sequestration: State of the Science, has assessed key areas for research and development (R\&D) for an understanding of carbon sequestration as a major tool for managing carbon emissions. Using present technology, estimates of sequestration costs are in the range of \$100 to $\$ 300 /$ ton of carbon emissions avoided. The goal of the program is to reduce the cost of carbon sequestration to $\$ 10$ or less per net ton of carbon emissions avoided by 2015 . Achieving this goal would save the U.S. trillions of dollars.

\section{$2.3 \quad$ Potential Market and Competition}

The total land area of the United States is 9,158,960 square kilometers. For spatially resolving the progress of carbon sequestration if one ASAC device is deployed per square kilometer, then the U.S. alone will require about 9.2 million units. This number is perhaps too ambitious. Sales volume in the thousands will offer economies of scale and the procurement cost of ASAC can be approximately $\$ 2,000$ per unit. This cost is only for InnoSense LLC's $\mathrm{CO}_{2}$ sensor system. The solar battery and the communication gear are commercial-off-the-shelf items.

Market potential may be estimated as short term or long term with some assumptions. The short term will be a period short enough that the market buyers and suppliers have very little time to react to new product demands, increases in prices, or other major changes. The long term refers to a longer period, where significant market adjustments can be made. Due to the long budgeting process for environmental field instrumentation, we will define the short term to be 5 years. Due to the long product development and testing cycle, as well as the period of time for new techniques to become generally accepted, we will define the long term to be 10 years. We estimate that in the short term deployment scenario, one ASAC will be utilized per $2,000 \mathrm{sq}$. $\mathrm{km}$ land area. Thus, the short term revenue from a sale of 4,600 units can potentially approach $\$ 9$ million. Assuming that each unit will require one sensor replacement per year and the price of the sensor monolith and calibration kit is $\$ 100$, then another $\$ 0.5$ million revenue can be realized from the disposables every year. Thus, this product will serve an attractive niche market in the short term.

Presently, there is no product in the market that can monitor atmospheric $\mathrm{CO}_{2}$ autonomously for a long period with resolution adequate for monitoring the progress of the carbon sequestration process. Commercial companies such as YSI Life Sciences and Ocean Optics currently have optical $\mathrm{CO}_{2}$ measurement device: YSI 8500 CO2 Monitor from YSI and FCO2$\mathrm{R}$ Fiber Optic $\mathrm{CO}_{2}$ Sensor from Ocean Optics. The YSI system is designed for the fermentation 
This Final Report complies with SBIR Rights notice set forth in FAR clause 52.227-20

industries where typically $5-10 \% \mathrm{CO}_{2}$ in air (v/v) is used and the system detects $1-25 \% \mathrm{CO}_{2}$ dissolved in aqueous medium. The YSI system requires calibration every seven days or sooner. Thus, this system is not designed for measuring atmospheric $\mathrm{CO}_{2}$ autonomously. The unit price of the YSI system is $\$ 8,900$ and the sensorhead costs $\$ 900$. The Ocean Optics system is also designed for the same applications as YSI's sensor. The unit price for the Ocean Optics $\mathrm{CO}_{2}$ sensor system is about $\$ 5,000$, and the replacement sensorhead is $\$ 499$. Thus, the ASAC device ISL is developing is expected to have a performance to price ratio superior to the commercially available devices. Affordable product price, superior quality and features, and friendly after-sales service will help ISL to achieve differentiation and retain market share. In a market where all vendors are equally susceptible to loss of brand and customer loyalty, ISL will reap rich benefits by ensuring shorter lead times and providing value-added features.

\section{0}

\section{DEGREE TO WHICH PHASE I HAS DEMONSTRATED TECHNICAL FEASIBILITY}

The purpose of the Phase I project was to demonstrate that a longer-lasting opto-chemical sensor for carbon dioxide can be materialized by continuously rehydrating the indicator and maintaining it in the proper state of ionization. The specific Phase I technical objectives were:

1. To establish that the sensing components can be incorporated into an ormosil matrix for facilitating rehydration via pores and channels for long term autonomous deployment.

2. To demonstrate that the indicator remains active in the ormosil monolith and can detect $\mathrm{CO}_{2}$ in the $0-500 \mathrm{ppm}$ range within a minute, potentially for a long time.

InnoSense LLC successfully met all objectives proposed for Phase I. The following sections detail our results. We would first discuss how we incorporated the $\mathrm{CO}_{2}$ indicator in the ormosil monolith and then we would show how we have established the long-term, autonomous use potential. 


\subsection{Objective 1: Constructing the Ormosil Monolith}

\subsubsection{Solution Phase Characterization of HPTS}

Prior to incorporating the $\mathrm{CO}_{2}$ indicator in the ormosil matrix, we performed spectroscopic studies of HPTS in the solution phase to assure that the indicator we are using matched reported spectral profile. Figure 3-1 shows the absorption characteristics of $0.1 \mathrm{mM}$ HPTS in water, $\mathrm{pH}$ adjusted to 8.0 with sodium hydroxide. Figure 3-2 shows the emission characteristics. These spectral profiles are consistent with literature data.

Various concentrations of $\mathrm{CO}_{2}$ were generated by diluting $1000 \mathrm{ppm} \mathrm{CO}_{2}$ from a certified tank with pure nitrogen. $\mathrm{CO}_{2}$ samples were carefully purged through the solution in a cuvette for 10 minutes prior to making absorption measurements using a Shimadzu Model 2401 UV/vis spectrophotometer. The emission measurements were made using a SPEX

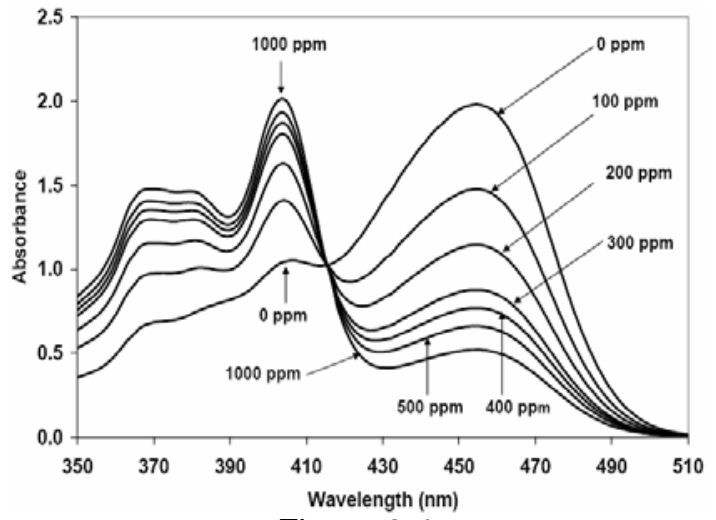

Figure 3-1

Absorption characteristics of $0.2 \mathrm{mM}$ HPTS in aqueous medium ( $\mathrm{pH} \mathrm{8)}$ at various concentrations of carbon dioxide FluoroMax 3 spectrofluorimeter

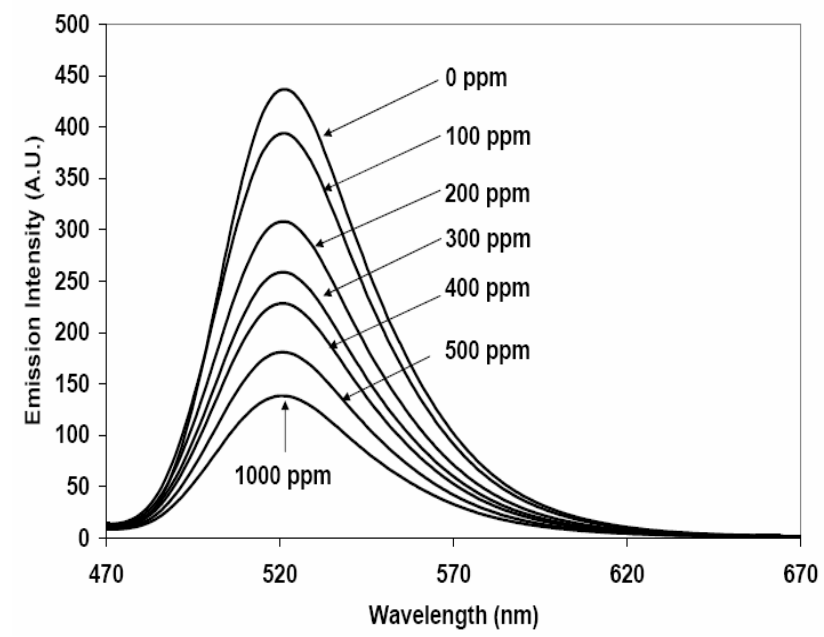

Figure 3-2

Emission characteristics of $0.2 \mathrm{mM}$ HPTS in aqueous medium $(\mathrm{pH} 8)$ at various concentrations of carbon dioxide

\subsubsection{Construction of Ormosil Monolith}

Fabrication of a crack-free, optically and mechanically suitable ormosil monolith was achieved by experimenting with a variety of formulations shown in Table 3-1. The chemical reagents used to make the indicator matrix were tetraethylorthosilicate (TEOS), polydimethylsiloxane hydroxyl-terminated (PDMS, $\mathrm{M}_{\mathrm{w}}=2000$ ), 3-aminopropyltriethoxysilane (APTES), 3- 
This Final Report complies with SBIR Rights notice set forth in FAR clause 52.227-20

glycidoxypropyltrimethoxysilane (GPTMS), tetramethylammonium hydroxide (TMAOH) 25\% aqueous solution, tetrabutylammonium hydroxide (TBAOH) 40\% aqueous solution, tetraoctylammonium hydroxide (TOAOH) 20\% solution in methanol, and 8-hydroxypyrene1,3,6-trisulfonate (HPTS), all purchased from Sigma-Aldrich.

Table 3-1: Various formulations for making the monoliths

\begin{tabular}{|c|c|c|c|}
\hline $\begin{array}{l}\text { Sol } \\
\text { ID }\end{array}$ & Ormosil Precursor & Catalyst & Observations \\
\hline \multirow[t]{2}{*}{ A } & $\begin{array}{l}\text { TEOS+APTES+PDMS } \\
(11: 10: 1) \text { molar ratio }\end{array}$ & TMAOH & Rapid hydrolysis and gelation \\
\hline & $\begin{array}{l}\text { TEOS+APTES+PDMS } \\
(11: 10: 1) \text { molar ratio }\end{array}$ & TBAOH & Clear; slow gelation \\
\hline \multirow[t]{3}{*}{ B } & $\begin{array}{l}\text { TEOS+APTES+GPTMS+PDMS } \\
(11: 5: 5: 1) \text { molar ratio }\end{array}$ & TMAOH & $\begin{array}{l}\text { Rapid hydrolysis and gelation } \\
\text { (concave top) }\end{array}$ \\
\hline & $\begin{array}{l}\text { TEOS+APTES+GPTMS+PDMS } \\
(11: 5: 5: 1) \text { molar ratio }\end{array}$ & TBAOH & $\begin{array}{l}\text { Clear; slow gelation ( } 2 \text { weeks for } \\
\text { monolith formation). Flat top surface }\end{array}$ \\
\hline & $\begin{array}{l}\text { TEOS+APTES+GPTMS+PDMS } \\
(11: 5: 5: 1) \text { molar ratio }\end{array}$ & TOAOH & $\begin{array}{l}\text { Clear; very long gelation time (5-6 } \\
\text { weeks) }\end{array}$ \\
\hline \multirow[t]{3}{*}{$\mathbf{C}$} & $\begin{array}{l}\text { TEOS+APTES+GPTMS+PDMS } \\
(11: 5: 5: 1) \text { molar ratio }\end{array}$ & $\begin{array}{l}\text { TBAOH } \\
(0.8 \mathrm{ml})\end{array}$ & $\begin{array}{l}\text { Clear; slow gelation (3-4 weeks for } \\
\text { monolith formation). Flat top surface }\end{array}$ \\
\hline & $\begin{array}{l}\text { TEOS+APTES+GPTMS+PDMS } \\
(11: 5: 5: 1) \text { molar ratio }\end{array}$ & $\begin{array}{l}\text { TBAOH } \\
(1.0 \mathrm{ml})\end{array}$ & $\begin{array}{l}\text { Hazy; slow gelation ( } 4-5 \text { weeks for } \\
\text { monolith formation). Flat top surface }\end{array}$ \\
\hline & $\begin{array}{l}\text { TEOS+APTES+GPTMS+PDMS } \\
(11: 5: 5: 1) \text { molar ratio }\end{array}$ & $\begin{array}{l}\text { TBAOH } \\
(1.2 \mathrm{ml})\end{array}$ & $\begin{array}{l}\text { Clear; slow gelation ( } 2 \text { weeks for } \\
\text { monolith formation). Flat top surface }\end{array}$ \\
\hline
\end{tabular}

Preparation of Sol: Sol solutions were made using TEOS, APTES, GPTMS and PDMS in the molar ratios indicated in Table 3-1. A typical formulation for Sol B was made by taking $5 \mathrm{~mL}$ of TEOS, $2.4 \mathrm{~mL}$ of APTES, $2.4 \mathrm{~mL}$ of GPTMS and $4.1 \mathrm{~mL}$ of PDMS in a polypropylene beaker placed in an ice bath, covered and stirred. In a separate test tube, $0.8 \mathrm{~mL}$ of the catalyst and $12.7 \mathrm{~mL}$ of ethanol were mixed and placed in the same ice-bath. After both solutions had cooled, the contents of the test tube were slowly added to the reagents in the beaker with stirring. The solution was allowed to mix for 3 hours and slowly allowed to warm to room temperature. The resulting sol was filtered using a $0.2 \mathrm{~mm}$ nylon filter and poured into polyethylene vials, sealed with parafilm with a few holes to allow for solvent evaporation and allowed to age at room temperature or in an isothermal oven at $40{ }^{\circ} \mathrm{C}$. The gelation and monolith formation were monitored on a daily basis and monoliths were considered ready for testing when the weight change measured on consecutive days was less than $0.1 \mathrm{mg}$. The aging times for monoliths varied with the recipe used. The formulation using Sol B and tetrabutylammonium hydroxide as the catalyst yielded good quality monoliths in the shortest time frame (2-3 weeks).

Incorporation of HPTS: The HPTS indicator has been embedded in the matrix by two methods. In Method A, $0.056 \mathrm{mM}$ of HPTS was dissolved in the ethanol-TBAOH mixture and added to the ormosil precursors, mixed as described, and cast into the vials. In Method B, HPTS was first modified in the form of an HPTS-tetraoctylammonium (TOA) ion pair based on the Principal Investigator's prior research on HPTS as $\mathrm{CO}_{2}$ indicator. ${ }^{7}$ The ion pair 
This Final Report complies with SBIR Rights notice set forth in FAR clause 52.227-20

between anionic HPTS and the tetraoctylammonium ion has the composition (HPTS)/(TOA) ${ }_{4}$ and was prepared as follows: $200 \mathrm{~g}$ of the trisodium salt of HPTS and the 4-fold molar equivalent (834 g) of tetraoctylammonium bromide (TOABr, Sigma-Aldrich) were dissolved in $30 \mathrm{~mL}$ of water containing $1 \%$ sodium carbonate and $30 \mathrm{~mL}$ of dichloromethane, respectively, and mixed in a separatory funnel. The ion-pair was extracted into the organic phase. The organic phase was collected and washed three times with $0.05 \mathrm{M}$ sodium hydroxide solution. The organic phase was separated and the organic solvent was evaporated to obtain the crystalline ion-pair. The purpose for using this bulky ion-pair is to prevent potential leaching of the indicator from the monolith. About $130 \mathrm{mg}$ of the ion-pair was dissolved in ethanol mixed with TBAOH and added to the ormosil precursors. Figure 3-3 shows the various processing steps involved in the formation of monoliths.

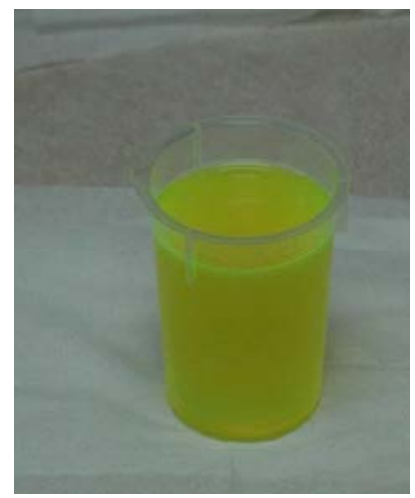

(a)

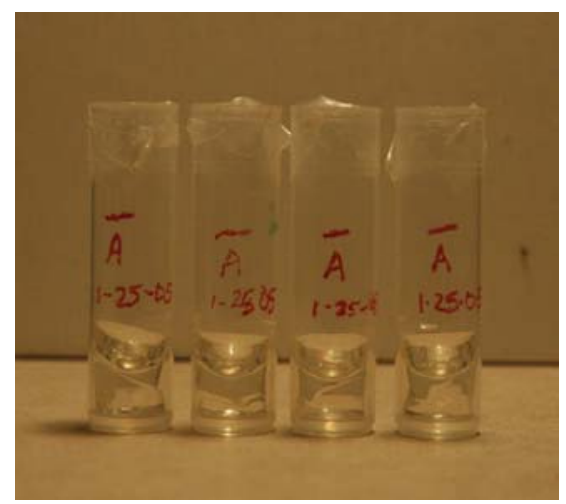

(d)

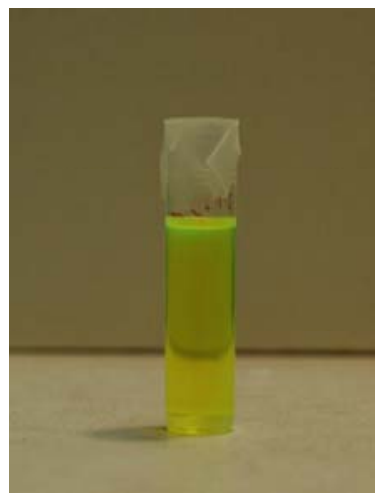

(b)

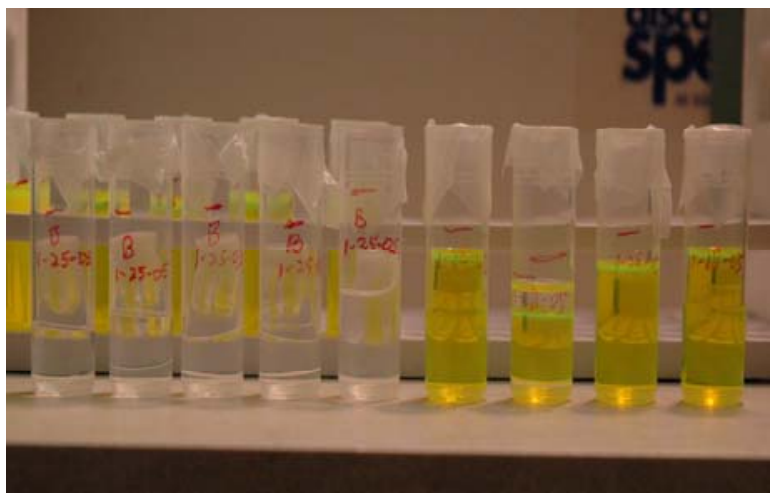

(c)

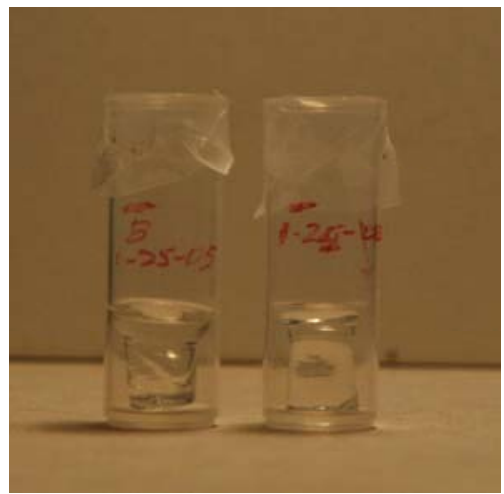

(e)

Figure 3-3

Various stages of the monolith formation. (a) precursor sol doped with HPTS after mixing warmed up to room temperature, (b) sol cast into polyethylene vials, (c) sols from different recipes in varying stages of gelation and aging at room temperature, (d) aging monoliths from

Sol A without indicator for identifying abnormalities such as cracking, deformation and a concave top surface, (e) monoliths from Sol B without the indicator.

In Figure 3-4, we show the differences in the monoliths that were formed using the recipe Sol $\mathrm{C}$ and TBAOH as the catalyst. The main differences were the amount of catalyst and the form of the HPTS indicator -- free or ion-paired. 
This Final Report complies with SBIR Rights notice set forth in FAR clause 52.227-20

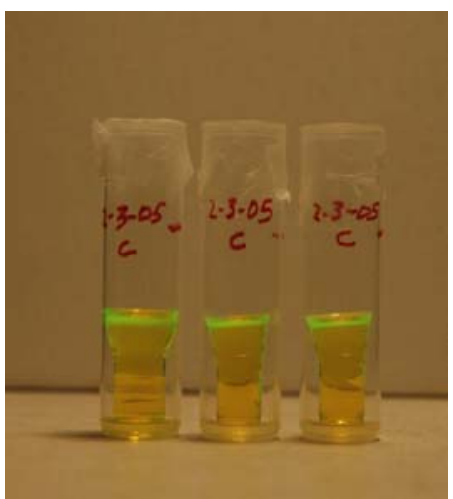

(a)

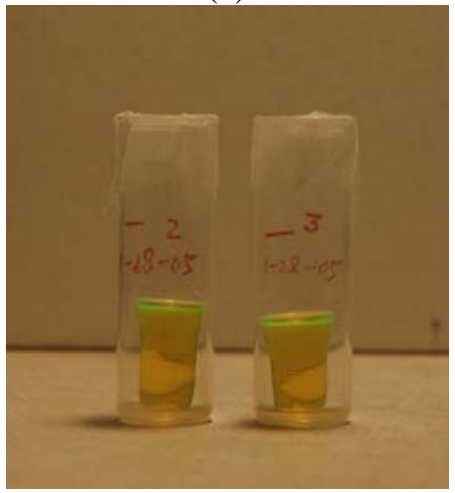

(d)

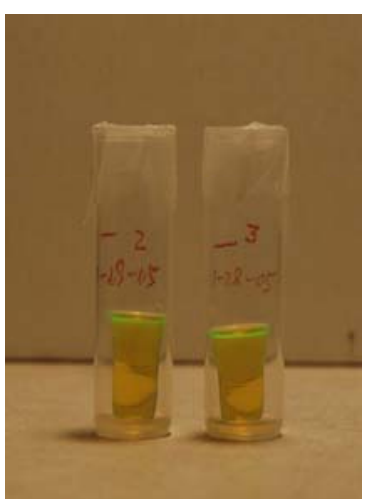

(b)

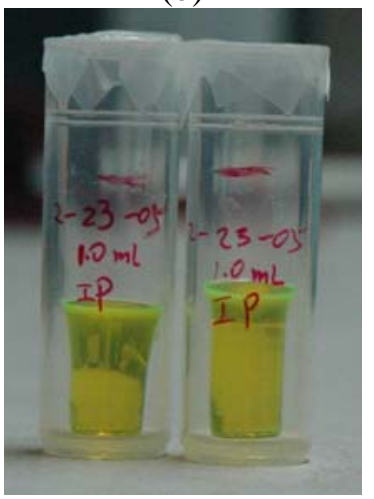

(e)

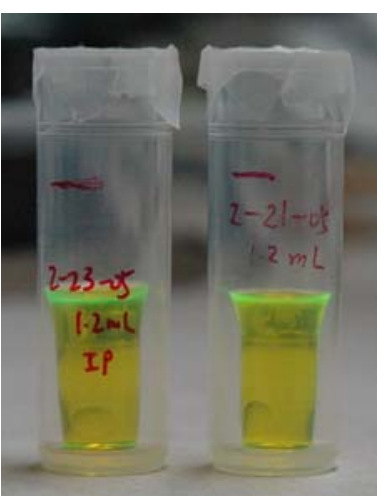

(c)

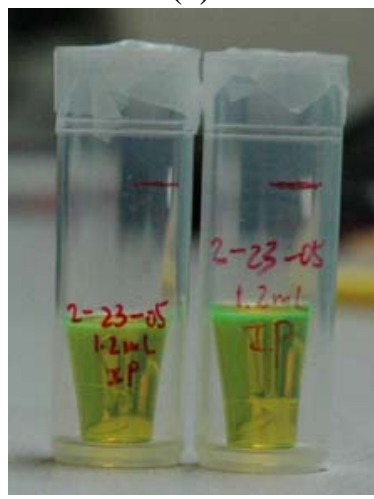

(f)

Figure 3-4

Effect of indictor type and catalyst concentration on the quality of monoliths.

In Figure 3-4(a), $1.2 \mathrm{~mL}$ of the catalyst was used with HPTS in its free form, while in 3-4(b) HPTS in the ion-pair form was used. Figure 3-4(c) compares a monolith containing HPTS in the ion-pair form (left image) with a monolith containing free form of HPTS (right image). Experimentally, the free form of HPTS did not completely dissolve in the ethanolic catalyst solution while the ion-pair form dissolved completely at the same concentration levels. From the monoliths that formed, those with ion-pair appear to have lower degree of shape distortion at the top compared to monoliths that have HPTS alone. Figures 3-4(d), (e) and (f) compare the effect of the catalyst composition on the monoliths. The indicator was used as the ion-pair in all three cases. In 3-4(d), where $0.8 \mathrm{~mL}$ catalyst was used, the gelation was slow with slight distortion at the top. In 3-4(e), $1.0 \mathrm{~mL}$ of the catalyst was used. We consistently observed a hazy structure, suggesting a more rapid hydrolysis of one or more precursor components and a constantly evolving microstructure, while for $1.2 \mathrm{~mL}$ of the catalyst (Figure 3-4(f)), we observed clear and undistorted monolith formation.

Characterization of Monoliths: Visual inspection of appearance was performed on all samples. Scanning electron micrographs of the fracture surface of monoliths containing free and ion-paired HPTS were obtained. The samples were analyzed at the Center for Surface Analysis of Materials at Case Western Reserve University, using a Hitachi S4500 FE-SEM. Mercury intrusion porosimetry was used to estimate the porosity of a monolith sample embedded with HPTS in the form of ion-pair. These measurements were carried out at Micromeritics Analytical Services, GA, using an AutoPore IV 9500 v1.06 instrument. 
Sol B yielded good quality monoliths when $1.2 \mathrm{~mL}$ of TBAOH was used as the catalyst and HPTS was used as ion-pair. The gelation time was about 2 weeks and the shrinkage was relatively lower (44\% in height, $14 \%$ across the top and $25 \%$ across the middle). Figure $3-5$ compares the microstructure and morphology of the fracture surface of two types of monolith samples - Sample A and Sample B.

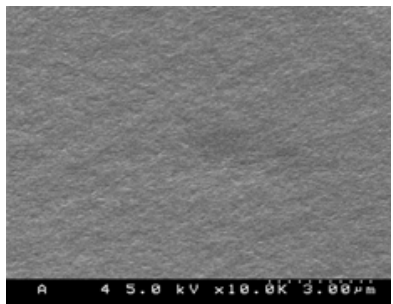

(a)

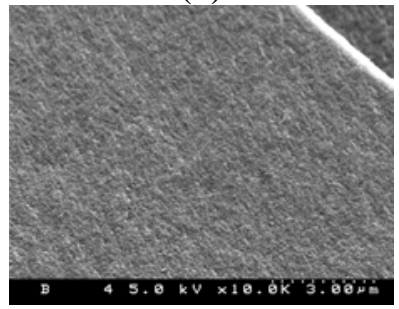

(c)

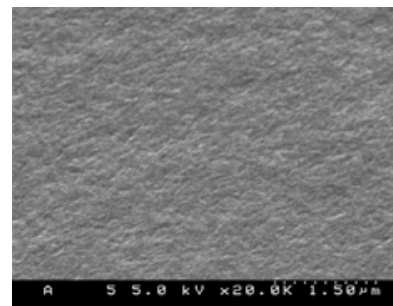

(b)

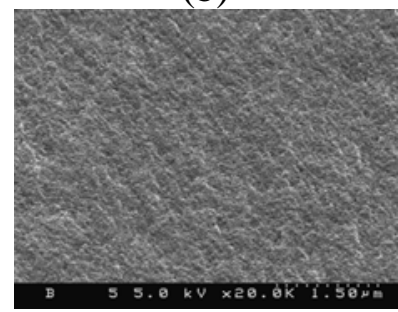

(d)

Figure 3-5

Scanning electron micrographs of monoliths containing free-form HPTS and HPTS in the form of ion-pair. (a) Sample A with free HPTS (x10k); (b) Sample A with free HPTS (x20k); (c)

Sample B with ion-paired HPTS (x10k); (d) Sample B with ion-paired HPTS (x20k)

Sample A contained the free form of HPTS and Sample B contained the ion-paired HPTS. Figures 3-5(a-b) show the features for Sample A and Figures 3-5(c-d) show the features of Sample B. The samples were fractured just prior to analysis and coated with a thin layer of PdAu alloy to prevent charging. Comparing samples A and B, the ion-paired HPTS (Sample B) appears to give more texture to the surface.

The porosity of the samples was studied with mercury porosimetry. The total pore area was estimated to be $39 \mathrm{~m}^{2} / \mathrm{g}$, which is comparable to a surface area of $32 \mathrm{~m}^{2} / \mathrm{g}$ reported by Nivens et al. ${ }^{27}$ The average pore diameter was estimated to be $\sim 14 \mathrm{~nm}$ while the median pore diameter was estimated to be $\sim 5 \mathrm{~nm}$. The porosity was estimated to be $15.3 \%$ from the bulk density measured at 0.51 psia $(1.15 \mathrm{~g} / \mathrm{ml})$ and skeletal density of $1.36 \mathrm{~g} / \mathrm{ml}$. Higher porosity is desirable for enhancing the sensitivity and decreasing sensor response time. In Phase II, the porosity would be optimized by varying the organic content of the ormosil.

Consideration for Using the Ormosil Monolith Approach: The Principal Investigator has experimented with a variety of sensing platforms for $\mathrm{CO}_{2}$ sensing, which include using HPTS solution directly into a small cell contained by $\mathrm{CO}_{2}$ permeable membrane, ${ }^{3,15-17}$ thin polymer film on waveguides, ${ }^{7}$ and sol-gel film on waveguides (this study was conducted under a NASA-Johnson Space Center funded SBIR project entitled "Biochemical Assays Using Novel Surface Plasmon Resonance Excitation,” Contract No. NAS9-19499, period of performance March 1996 - September 1998, Technical Monitor Ms. Melody Anderson (281-483-3318), 
This Final Report complies with SBIR Rights notice set forth in FAR clause 52.227-20

unpublished results). These platforms did not succeed toward developing a $\mathrm{CO}_{2}$ sensor for long term, autonomous operation because of the aforementioned drying issues.

The ormosil monolith allows us to integrate ion-paired HPTS during the monolith fabrication process, and also provides a network of pores and channels for rehydrating the indicator continuously with alkaline buffers. The bulky HPTS-TOA ion-pair substantially reduces leaching and photobleaching of the HPTS, and its water of crystallization ${ }^{12}$ also provides the sensing chemistry with limited hydration for $\mathrm{CO}_{2}$ dissolution.

The critical aspect of the feasibility demonstration involves the continuous rehydration of the $\mathrm{CO}_{2}$ sensor and assuring that the indicator could maintain the anionic form for responding to varying levels of $\mathrm{CO}_{2}$. Toward that goal, we assembled a test cell as shown in Figure 3-6.

\section{Detector Orthogonal to} Blue LED

\section{Ormosil Monolith \\ Reservoir with pH 8 Buffer}

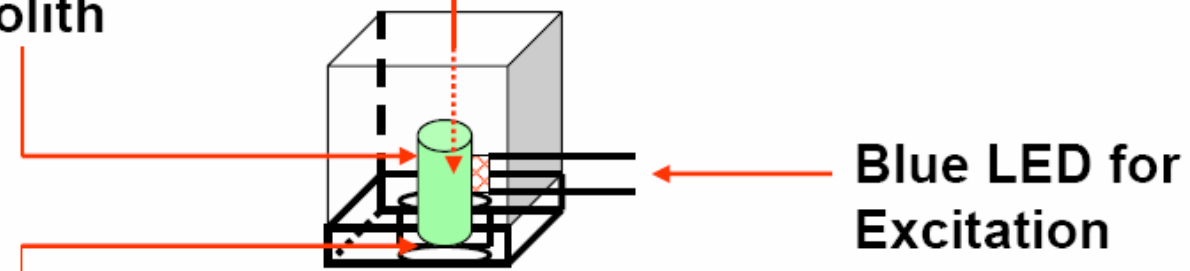

Phase I test setup. The ormosil monolith was positioned in a cavity containing pH 8 buffer, which assured continuous rehydration and reionization.

We constructed a test cell using black Delrin polymer block. A cavity was machined at the base of the polymer block for soaking the bottom of the ormosil monolith (5 mm diameter) into pH 8 sodium bicarbonate buffer. This test cell was placed inside a metal housing equipped with gas inlet and outlet ports. A blue LED, with a cut-off filter placed after the LED to allow only the blue light into the monolith, was used for excitation. A silicon photodiode, with built-in preamplifier and a cut-off filter placed before the photodiode for collecting only the HPTS emission, was used for signal collection. The LED and photodiode were mounted orthogonally into the Delrin block. The detector signal was amplified further and the electrical signal was collected using data acquisition system (National Instruments) and LabView software. The signal was processed using Fast Fourier Transform algorithm and a desktop computer. Various $\mathrm{CO}_{2}$ concentrations were generated by diluting $1000 \mathrm{ppm} \mathrm{CO}_{2}$ from a certified tank with nitrogen utilizing mass flow controllers. 
This Final Report complies with SBIR Rights notice set forth in FAR clause 52.227-20

\subsubsection{Response Time and Reversibility}

The monoliths we used in the Phase I investigation were approximately $20 \mathrm{~mm}$ long and $5 \mathrm{~mm}$ in diameter. To determine the response time of the sensor, we changed the $\mathrm{CO}_{2}$ concentration from $0 \mathrm{ppm}$ to $500 \mathrm{ppm}$. The $\mathrm{CO}_{2}$ sample was administered to the test cell ( $200 \mathrm{~mL}$ volume) at a rate of $1 \mathrm{~L} /$ minute. Figure 3-7 shows the experimental results. From the raw data, we determined that the sensor response to $90 \%$ change in the signal $\left(\mathrm{T}_{90}\right)$ occurs in 40 seconds with a $90 \%$ recovery time of 60 seconds.

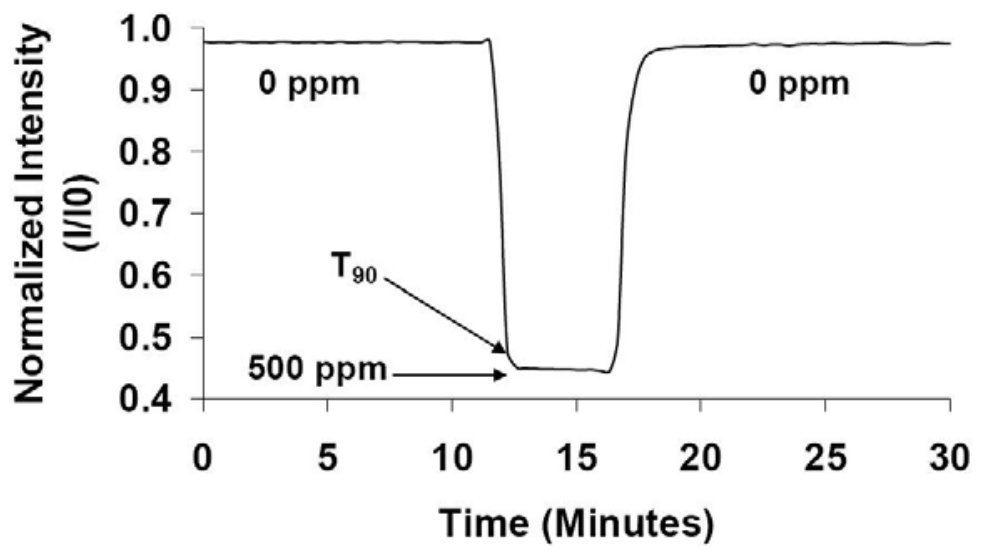

Figure 3-7

Response characteristics of the $\mathrm{CO}_{2}$ sensor. The integration time was 1 second. The output of a blue LED was filtered through a low-pass filter $\left(\lambda_{\text {cutoff }}>500 \mathrm{~nm}\right)$ for excitation purposes. The fluorescence signal was filtered through a high-pass filter $\left(\lambda_{\text {cutoff }}<500 \mathrm{~nm}\right)$ prior to detection by a photodetector.

The 40-second response time is not an inherent limitation of the sensor. This time is a function of the test setup with $200 \mathrm{~mL}$ air volume of nitrogen, which has to be replaced with $500 \mathrm{ppm}$ $\mathrm{CO}_{2}$. As will be discussed in the Phase II work plan, we would design a flow cell just surrounding the $\mathrm{CO}_{2}$ sensor (Figure 5-2, Section 5.1 under Task 3, total volume of flow cell 10 $\mathrm{mL}$ ), and we expect the response time to be under 10 seconds). The response time and recovery time aspects would be investigated during Phase II using monoliths of different porosities. .

\subsubsection{Dynamic Detection Range}

Figure 3-8 shows the sensor response in the $0-1000 \mathrm{ppm}$ range. 
This Final Report complies with SBIR Rights notice set forth in FAR clause 52.227-20

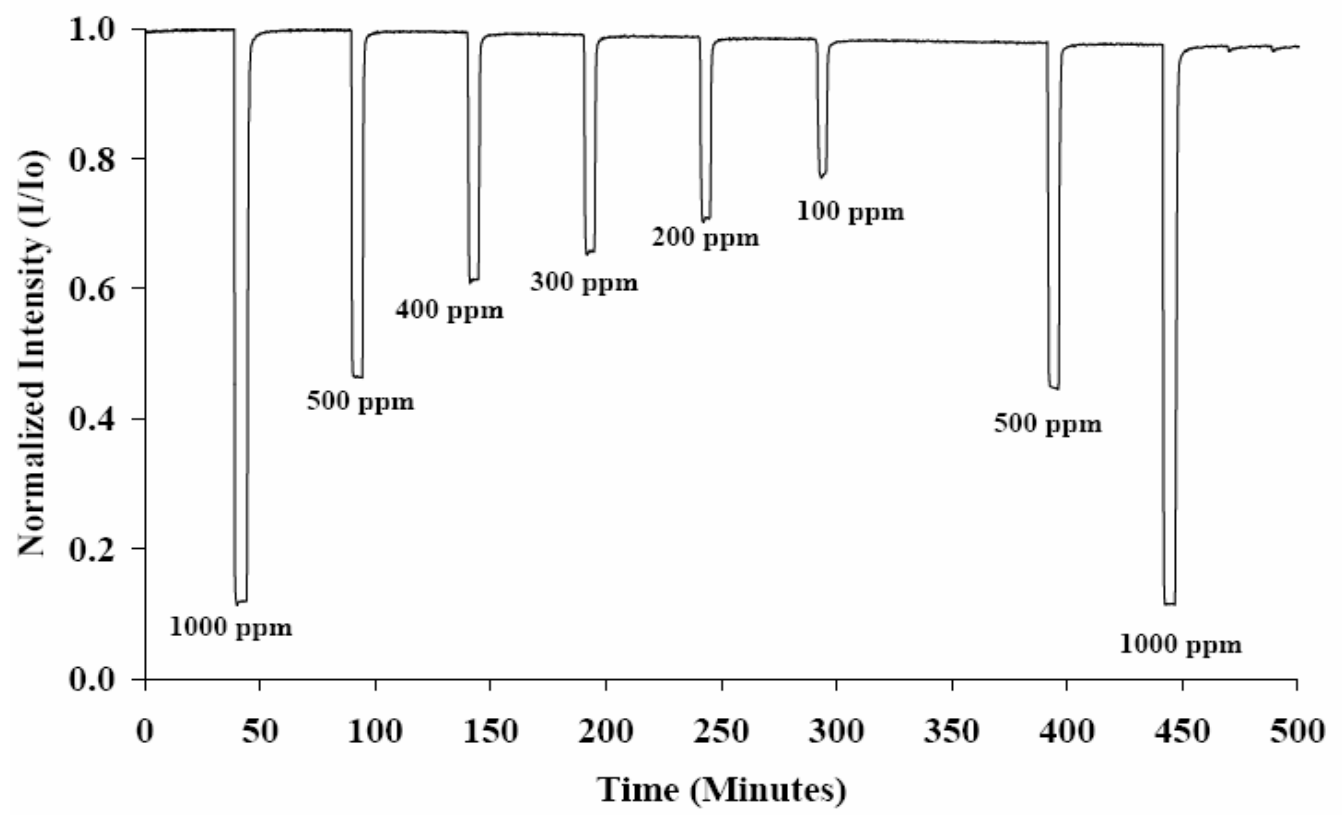

Figure 3-8

$\mathrm{CO}_{2}$ sensor response in the $0-1000 \mathrm{ppm}$ range.

The sensor responds nicely over the $0-1000$ ppm range. The sensor response over the entire range appears to show a non-linear fit. Because fine-tuning would be done in Phase II, we reserved the curve-fitting exercise in the $0-1000 \mathrm{ppm}$ range for Phase II. Since atmospheric $\mathrm{CO}_{2}$ levels hover in the 360-380 ppm levels, we carried out regression analysis in the 0-400 ppm range. Results are shown in Figure 3-9.

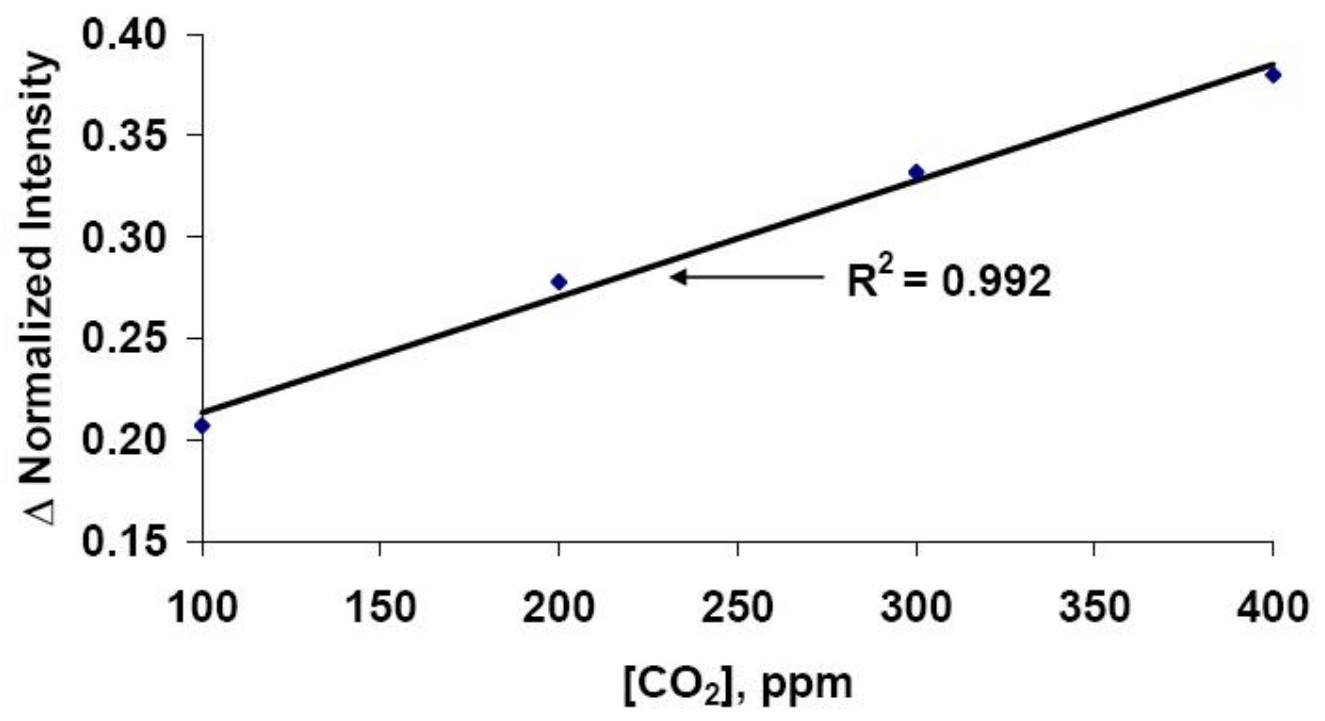

Figure 3-9

Regression fit of the sensor response for $0-400 \mathrm{ppm} \mathrm{CO}_{2}$.

Sensitivity Calculation: The uncertainty in the baseline is 0.001 volts and the signal change for $100 \mathrm{ppm} \mathrm{CO}_{2}$ is 0.23 volts. For a signal to noise ratio (SNR) of 1, we calculate that the sensitivity of the sensor in its present state of development approximates $0.4 \mathrm{ppm} \mathrm{CO}_{2}$. At this stage of our project, this represents the best case scenario. We expect to improve the sensor 
This Final Report complies with SBIR Rights notice set forth in FAR clause 52.227-20

performance at least by a factor of 5 during Phase II by fine-tuning the sensor fabrication process and implementing ratiometric measurements. The sensitivity of a carbon dioxide sensor is linked to the pKa of HPTS and to the nature of the buffer that surrounds it. ${ }^{12}$ During Phase II fine-tuning, we would evaluate the sensor with buffers in the $\mathrm{pH}$ 7-10 range. The effects of ionic strengths would also be explored since it is a fact that electrolyte concentration affects chemical equilibria.

\subsubsection{Potential for Long-Term, Autonomous Performance.}

The long-term, autonomous performance potential of the sensor was evaluated in Phase I by exposing the sensor to ambient levels of $\mathrm{CO}_{2}$ for 8 weeks. The test cell was carefully covered with black flannel fabric, and the buffer in the reservoir was replenished periodically. The sensor was equilibrated for two hours, under ambient atmosphere, prior to commencing data acquisition. The sensor signal was recorded every 30 minutes. Figure 3-10 shows the longterm sensor performance during the Phase I study.

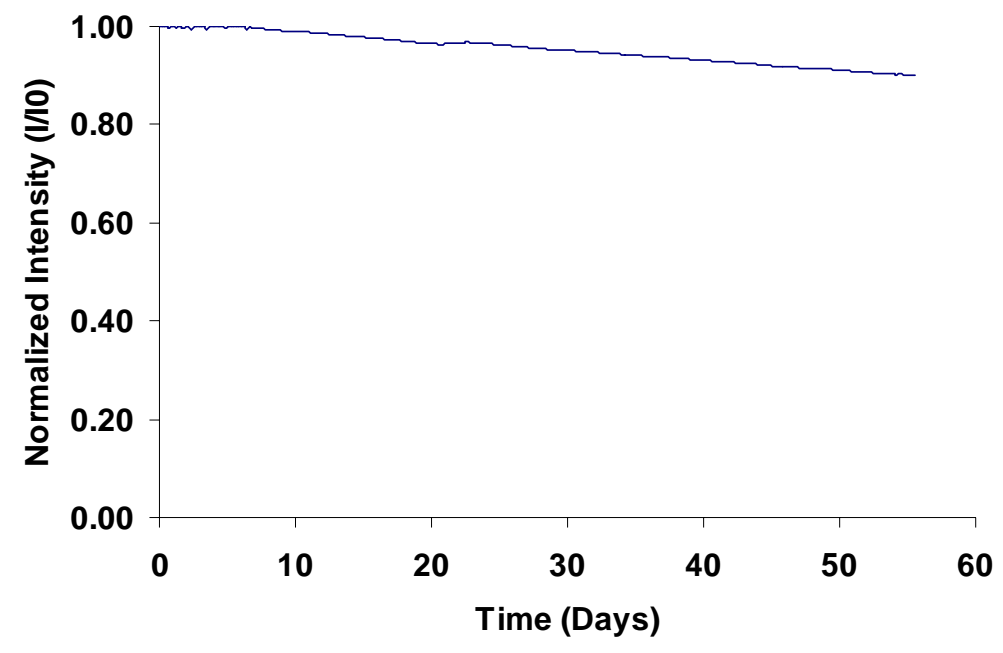

Figure 3-10

Phase I investigation of long-term use potential

The sensor showed 9\% drift in baseline over eight weeks. This drift can be attributed to slow leaching and/or photobleaching of the indictor as well as electronic drift including deterioration of the LED output. As would be discussed in the Phase II work plan (Section 5.1, Tasks 4 and 5), this drift would be mitigated by ratiometric measurements. The crucial part of the Phase I evaluation was to determine if the sensor was still capable of responding to $\mathrm{CO}_{2}$ in the same manner before the long-term test. We tested the sensor again over the 0-1000 ppm range. Figure 3-11 shows the performance data. 
This Final Report complies with SBIR Rights notice set forth in FAR clause 52.227-20

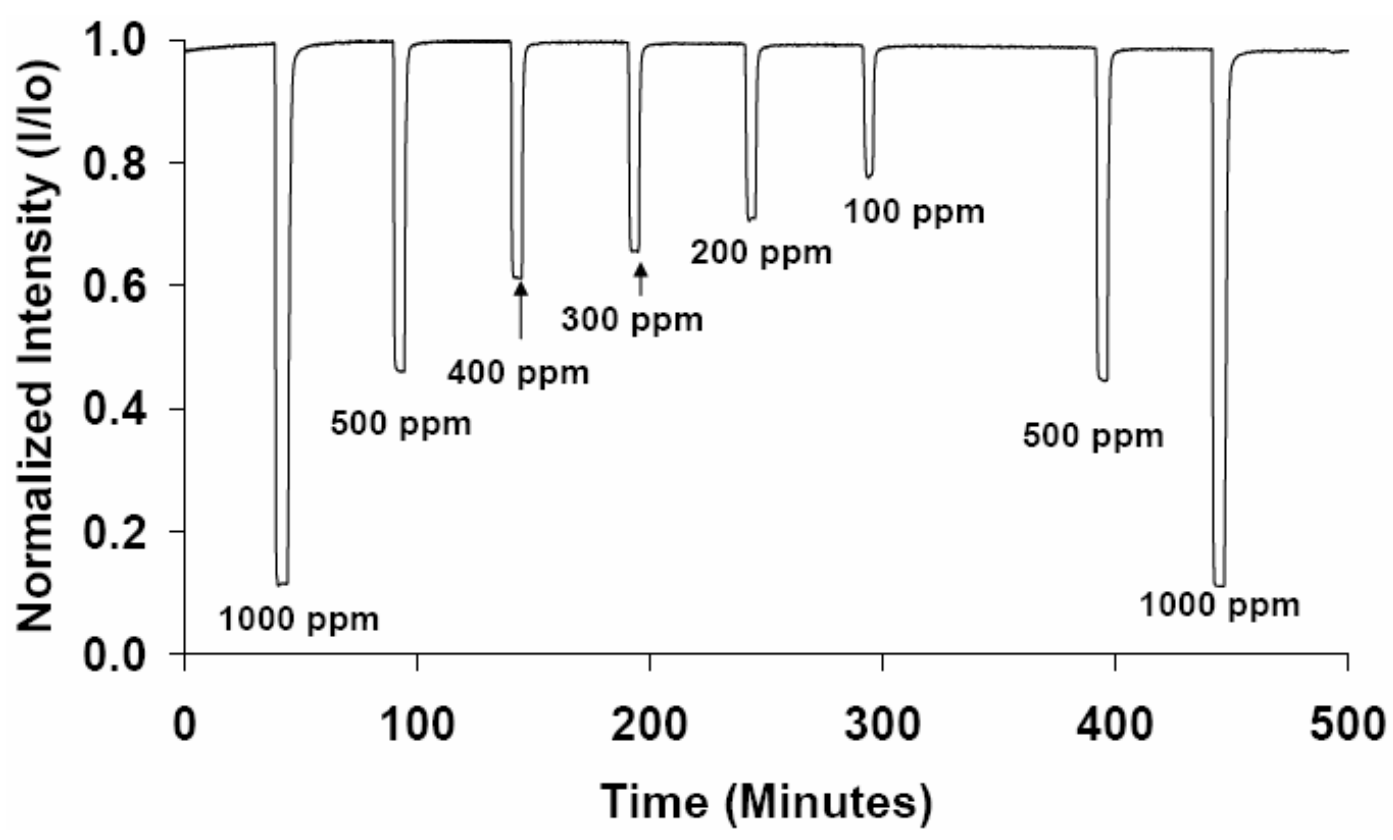

Figure 3-11

Evaluation of performance after the sensor was exposed to atmospheric $\mathrm{CO}_{2}$ continuously for 8 weeks.

The data acquisition protocol was same as the one used for Figure 3-8. Although the initial baseline was different, we found that the \% change in signal for a given concentration of $\mathrm{CO}_{2}$ remained similar before and after the long-term test. This shows that the sensor maintained its characteristics, and long-term application is possible without calibration.

\subsection{Phase I Conclusions and Justification of Transitioning to Phase II}

In this Phase I project, InnoSense LLC set out to demonstrate that the use of a reservoir approach for rehydrating the $\mathrm{CO}_{2}$ indicator and maintaining it in the proper anionic form would allow the construction of an autonomous, longer-lasting $\mathrm{CO}_{2}$ sensor for ground-based measurements in support of DOE's carbon sequestration program. The results obtained in this project met or exceeded the performance goals set at the beginning of Phase I.

The Phase I project also allowed us to identify the areas where Phase II efforts should be focused. The goal of our Phase II effort is to construct a sensor prototype that is consistent with our commercial goals of a low-cost, autonomous sensor system. We would verify performance of the Phase II prototype by a third party. InnoSense LLC has teamed with Dr. Hank Loescher of the Department of Forest Science, Oregon State University for conducting the independent performance verification toward the end of Phase II. InnoSense LLC (ISL) has committed \$50,000 Phase II co-funding for successful execution of the Phase II project. ISL has also received firm commitment of Phase III follow-on funding $(\$ 400,000)$ form Environmental Instrumentation Systems (Concord, CA) for commercializing the $\mathrm{CO}_{2}$ sensor.

The Principal Investigator, Dr. Kisholoy Goswami, has 24 years of experience in optical sensor development and holds 11 U.S. patents on optical sensors for trace chemical analysis. Dr. Goswami played the key role in developing the world's first commercial fiber optic chemical sensor for hydrocarbons (at FiberChem, a Nevada corporation, where he was the Director of Research, http://www.monitoreurope.com/products/water/petrosense/). The PI also has 
This Final Report complies with SBIR Rights notice set forth in FAR clause 52.227-20

hands-on experience in commercialization, having raised \$3M for the Phase III development of the above mentioned hydrocarbon sensor at FiberChem. ISL has assembled a proficient technical team having 70 cumulative years of experience in developing commercially viable optical sensor technologies for assuring successful completion of the project. 
1. (a) D. Baldocchi, “Abuout the FLUX network,” http://public.ornl.gov/ameriflux/abouthistory.shtml, dated April 7, 2005.

(b) K. Schulz, M.L. Jensen, B.B. Balsley, K. Davis, J.W. Birks, “Tedlar bag sampling technique for vertical profiling of carbon dioxide through the atmospheric boundary layer with high precision and accuracy,” Environmental Science \& Technology, 38(13), pp. 3683-3688, 2004.

(c) L. Dilling, S.C. Doney, J. Edmonds, K.R. Gurney, R. Harriss, D. Schimel, B. Stephens, G. Stokes, "The role of carbon cycle observations and knowledge in carbon management,” Annual Review of Environment and Resources, 28, pp. 521-558, 2003.

(d) L.R. Kuck, T. Smith, B.B. Balsley, D. Helmig, T.J. Conway, P.P. Tans, K. Davis, M.L. Jensen, J.A. Bognar, R.V. Arrieta, R. Rodriquez, J.W. Birks, "Measurements of landscape-scale fluxes of carbon dioxide in the Peruvian Amazon by vertical profiling through the atmospheric boundary layer," Journal of Geophysical ResearchAtmospheres, 105(D17), pp. 22137-22146, 2000.

(d) L.R. Kuck, R.D. Godec, P.P. Kosenka, J.W. Birks, "High precision conductometric detector for the measurement of atmospheric carbon dioxide," Analytical Chemistry, 70(22), pp. 4678-4682, 1998.

2. Y. Amao, N. Nakamura, "Optical $\mathrm{CO}_{2}$ sensor with the combination of colorimetric change of alpha-naphtholphthalein and internal reference fluorescent porphyrin dye," Sensors and Actuators B-Chemical, 100 (3), pp. 347-351, 2004.

3. K. Goswami, J.A. Kennedy, D.K. Dandge, S.M. Klainer, J.M. Tokar, "A fiber optic chemical sensor for carbon dioxide dissolved in sea water," SPIE Proc., Chemical, Biochemical, and Environmental Sensors, Vol. 1172, pp. 225-230, 1989.

4. M.D. DeGrandpre, "Multiwavelength detection for drift compensation in fiber optic chemical sensors," SPIE Proc., Chemical, Biochemical, and Environmental Fiber Sensors V, Vol. 2068, pp. 216-223, 1994.

5. C. von Bultzingslowen, A.K. McEvoy, C. McDonagh, B.D. MacCraith, I. Klimant, C. Krause, O.S. Wolfbeis, "Sol-gel based optical carbon dioxide sensor employing dual luminophore referencing for application in food packaging technology," Analyst, 127(11), pp. 1478-1483, 2002.

6. D.A. Nivens, M.V. Schiza, S.M. Angel, "Multilayer sol-gel membranes for optical sensing applications: single layer $\mathrm{pH}$ and dual layer $\mathrm{CO}_{2}$ and $\mathrm{NH}_{3}$ sensors,” Talanta, 58, pp. 543-550, 2002.

7. O.S. Wolfbeis, B. Kovacs, K. Goswami, S.M. Klainer, "Fiber-optic fluorescence carbon dioxide sensor for environmental monitoring," Mikrochimica Acta, 129(N3-4), pp. 181-188, 1998.

8. J.W. Parker, O. Laskin, C. Yu, M.L. Lau, S. Klima, R. Fisher, I. Scott, B.W. Atwater, "Fiber optic sensor for $\mathrm{pH}$ and carbon dioxide using a self-referenced dye," Analytical Chemistry, 65, 17, pp. 2329-2334, 1993.

9. N. Opitz, D.W. Lübbers, "The $\mathrm{pCO}_{2} / \mathrm{pO}_{2}$ optrode: $\mathrm{A}$ new probe for measuring $\mathrm{pCO}_{2}$ and $\mathrm{pO}_{2}$ of gases and liquids,” Z. Naturforsch, 30C, pp. 532-533, 1975. 
This Final Report complies with SBIR Rights notice set forth in FAR clause 52.227-20

10. Z. Zhujun, W.R. Seitz, “A fluorescence sensor for quantifying $\mathrm{pH}$ in the range from 6.5 to 8.5,” Anal. Chim. Acta, 160, pp. 47-51, 1984.

11. C. Munkholm, D.R. Walt, P.F. Milanovich, "Fiber optic sensor for $\mathrm{CO}_{2}$ analysis," Talanta, 35, p. 109, 1988.

12. A. Mills, A. Lepre, L. Wild, "Breath by breath measurement of carbon dioxide using a plastic film optical sensor,” Sensors and Actuators B- Chemical, 39(1-3), pp. 419-425, 1997.

13. B.H. Weigl, A. Holobar, W. Trettnak, I. Klimant, H. Kraus, P. Leary, O.S. Wolfbeis, "Optical triple sensor for measuring $\mathrm{pH}$, oxygen and carbon dioxide," J. Biotechnol., 32(2), pp. 127-138, 1994.

14. M.D. DeGrandpre, M.M. Baehr, T.R. Hammar, "Calibration-free optical chemical sensors,” Analytical Chemistry, 71, pp. 1152-1159, 1999.

15. J.M. Tokar, W.E. Woodward, K. Goswami, "The measurement of oceanic biogeochemical compounds using fiber optic chemical sensors," Conference Proc., Oceans '89, Seattle, Washington, September 18-21, 1989.

16. J.M. Tokar, W.E. Woodward, K. Goswami, "Fiber optic chemical sensors: Exploring the light fantastic," Sea Technology, Vol. 31, No. 4, pp. 45-49, 1990.

17. J.M. Tokar, W.L. Pugh, K. Goswami, "The use of fiber optic sensors for in-situ chemical measurements in the ocean," Geotechnical Engineering of Ocean Waste Disposal, ASTM STP 1087, Demars, K.R., and Chaney, R.C., (Eds.), Amer. Soc. for Testing and Materials, Philadelphia, pp. 65-75, 1990.

18. J.C. Seiter, M.D. DeGrandpre, "Redundant chemical sensors for calibration-impossible applications,” Talanta, 54(1), pp. 99-106, 2001.

19. E. A. Mendoza, A. Khalil, D. Robinson, J. Sorenson, A. Iossi, K. Goswami, R. A. Lieberman, “Integrated optic sensor for spacesuit atmospheric quality,” SAE Publication No. 961421, July 1996.

20. S. Aubonnet, H.F. Barry, C. von Bultzingslowen, J.M. Sabattie, B.D. MacCraith, "Photo-patternable optical chemical sensors based on hybrid sol-gel materials," Electronics Letters, 39 (12), pp. 913-914, 2003.

21. P. Lavin, C.M. Mcdonagh, B.D. Maccraith, "Optimization of Ormosil films for optical sensor applications,” Journal of Sol-Gel Science and Technology, 13(1-3), pp. 641645, 1998.

22. C. Malins, B.D. MacCraith, "Dye-doped organically modified silica glass for fluorescence based carbon dioxide gas detection,” Analyst, 123(11), pp. 2373-2376, 1998.

23. M.R. Shahriari, M.T. Murtagh, H.C. Kwon, "Ormosil thin films for chemical sensing platforms,” Proc. SPIE, Vol. 3105, pp. 40-51, Chemical, Biochemical and Environmental Fiber Sensors IX; Robert A. Lieberman; Ed., 1997.

24. W. Jin, J. D. Brennan, "Properties and applications of proteins encapsulated within solgel derived materials,” Anal. Chim. Acta, 461, pp. 1-36, 2002.

25. J.D. Mackenzie, Y.J. Chung, Y. Hu, "Rubbery Ormosils and their Applications," J. Non-Cryst. Solids, 147/148, 271, 1992. 
This Final Report complies with SBIR Rights notice set forth in FAR clause 52.227-20

26. J.D. Mackenzie, E.P. Bescher, "Structure, Properties and Potential Applications of Ormosils," Sol-Gel Sci. Tech., 13, 371, 1998.

27. D.A. Nivens, Y. Zhang, S.M. Angel, "A fiber-optic pH sensor prepared using a basecatalyzed organo-silica sol-gel.” Analytica Chimica Acta, Vol. 376, pp. 235-245, 1998. 